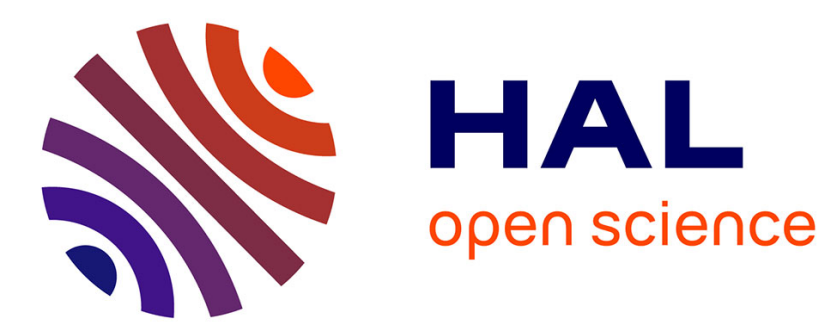

\title{
Real-time imaging of acoustic waves on a bulk acoustic resonator
}

\author{
T. Fujikura, O. Matsuda, D.M. Profunser, O.B. Wright, J. Masson, S.
} Ballandras

\section{- To cite this version:}

T. Fujikura, O. Matsuda, D.M. Profunser, O.B. Wright, J. Masson, et al.. Real-time imaging of acoustic waves on a bulk acoustic resonator. Applied Physics Letters, 2008, 93 (26), pp.261101. 10.1063/1.3053074 . hal-00532920

\section{HAL Id: hal-00532920 \\ https://hal.science/hal-00532920}

Submitted on 21 Apr 2021

HAL is a multi-disciplinary open access archive for the deposit and dissemination of scientific research documents, whether they are published or not. The documents may come from teaching and research institutions in France or abroad, or from public or private research centers.
L'archive ouverte pluridisciplinaire HAL, est destinée au dépôt et à la diffusion de documents scientifiques de niveau recherche, publiés ou non, émanant des établissements d'enseignement et de recherche français ou étrangers, des laboratoires publics ou privés. 


\title{
Real-time imaging of acoustic waves on a bulk acoustic resonator
}

\author{
Takashi Fujikura, ${ }^{1}$ Osamu Matsuda, ${ }^{1}$ Dieter M. Profunser, ${ }^{1}$ Oliver B. Wright, ${ }^{1, a)}$ \\ Jeremy Masson, ${ }^{2}$ and Sylvain Ballandras ${ }^{2}$ \\ ${ }^{1}$ Division of Applied Physics, Graduate School of Engineering, Hokkaido University, \\ Sapporo 060-8628, Japan \\ ${ }^{2}$ FEMTO-ST, UMR CNRS 6174, 32 Ave. de l'Observatoire, 25044 Besançon Cedex, France
}

(Received 1 October 2008; accepted 31 October 2008; published online 29 December 2008)

\begin{abstract}
Time resolved images of acoustic waves in the $100 \mathrm{MHz}-2.2 \mathrm{GHz}$ range are obtained for an electrically excited thin-film bulk acoustic wave resonator by means of an ultrafast optical technique. Electrical pulses, synchronized to ultrashort laser pulses, piezoelectrically excite the device, and synchronous near-infrared laser pulses interferometrically detect surface motion. The frequency dispersion is extracted using spatiotemporal Fourier transforms, revealing both longitudinal and surface acoustic modes. () 2008 American Institute of Physics.
\end{abstract}

[DOI: $10.1063 / 1.3053074]$

Surface acoustic waves (SAWs) are widely applied in the wireless communications industry to filter electromagnetic waves at $\sim 1 \mathrm{GHz}$ because the acoustic wavelength at such frequencies is typically a few microns, convenient for device miniaturization. ${ }^{1,2}$ The operation frequency of these devices depends on the spatial period of the interdigital electrodes that piezoelectrically generate the SAWs. Because of the precise patterning required for these electrodes for frequencies above $\sim 2 \mathrm{GHz}$, interest has recently focused on alternative designs based on bulk acoustic waves. In particular, thin-film bulk acoustic wave (BAW) resonators driven by piezoelectric films are showing promise: ${ }^{2-6}$ they provide low insertion losses, display good rejection characteristics (i.e., high $Q$-factors $Q>1000$ ), and do not require piezoelectric substrates. The frequency of operation is inversely proportional to the thickness, allowing simple fabrication of compact high frequency devices by suitable choice of film thickness. Applications to mass, temperature, or pressure sensing have also been reported. ${ }^{1,7}$

The bandwidth of BAW and SAW resonators depends on the acoustic loss, and imaging techniques for the acoustic field based on optical interferometry or atomic force microscopy have proven invaluable for the direct monitoring of device operation and acoustic wave leakage. ${ }^{8-12}$ These methods rely on frequency domain measurements and require sequential increments in frequency in order to cover the required frequency range. For the optical methods, in particular, it has proved difficult to extend operation to above $2 \mathrm{GHz}$.

In the case when SAW are excited and detected by ultrashort optical pulses, real-time interferometric imaging in the time domain has proved fruitful up to $\sim 1 \mathrm{GHz}{ }^{13,14}$ Here we extend this real-time optical detection method for application to imaging electrically driven BAW or SAW devices by the use of a hybrid electrical and optical technique. We demonstrate the method up to $\sim 2 \mathrm{GHz}$ on a BAW resonator and derive the acoustic dispersion relation by means of spatiotemporal Fourier transforms.

The experimental setup is shown in Fig. 1(a). Optical pulses of duration $\sim 200 \mathrm{fs}$, wavelength of $830 \mathrm{~nm}$, and repetition rate of $76 \mathrm{MHz}$ from a Ti:sapphire laser are used for

${ }^{\text {a)} E l e c t r o n i c ~ m a i l: ~ a s s p @ ~ k i n o-a p . e n g . h o k u d a i . a c . j p . ~}$ the dual purpose of generating electrical pulses to excite a BAW resonator and for the detection of the resulting surface motion. A small portion of the laser beam is guided to a photodetector of bandwidth $\sim 3 \mathrm{GHz}$ (Hamamatsu Photonics, G9842). The photodetector is connected to a wideband amplifier whose output is connected to the BAW device. The electrical pulses driving the device have $\sim 0.3 \mathrm{~ns}$ duration and a repetition rate of $76 \mathrm{MHz}$ (period of $13.2 \mathrm{~ns}$ ), that is identical to that of the laser pulses. The optical beam before the photodetector is modulated at $1 \mathrm{MHz}$ by an acousticoptic modulator (AOM) for purposes of synchronous lock-in detection. The spectrum of the electrical excitation as measured with a spectrum analyzer with the device disconnected is shown in Fig. 1(b), showing frequency components in steps of $76 \mathrm{MHz}$ up to $\sim 3 \mathrm{GHz}$.

The rest of the laser beam-the probe light-passes through a $4 \mathrm{~m}$ delay line (13 ns delay). We use a common-
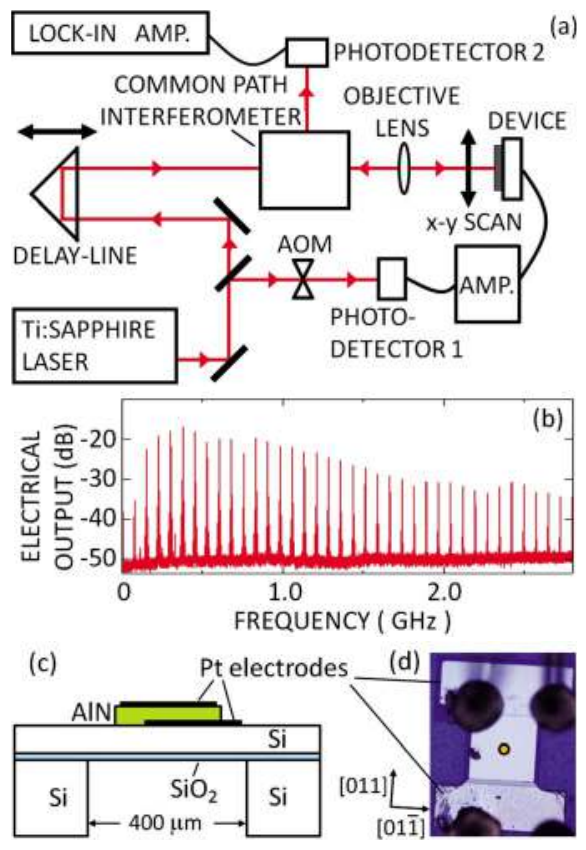

FIG. 1. (Color online) (a) Experimental setup. AOM: acousto-optic modulator. AMP: amplifier. (b) The spectrum of the electrical output from the amplifier. (c) Schematic cross section of the BAW resonator. (d) Optical micrograph of the BAW resonator, with Si crystal axes indicated. The central dot shows the location of the single-point measurements. 


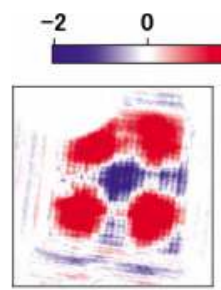

(a) $219 \mathrm{ps}$

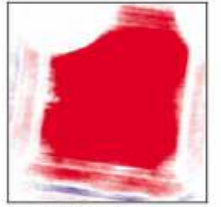

(b) $6570 \mathrm{ps}$
$220 \mu \mathrm{m} \times 220 \mu \mathrm{m}$

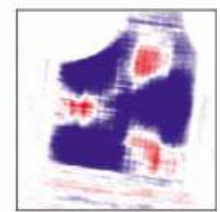

(c) $9198 \mathrm{ps}$
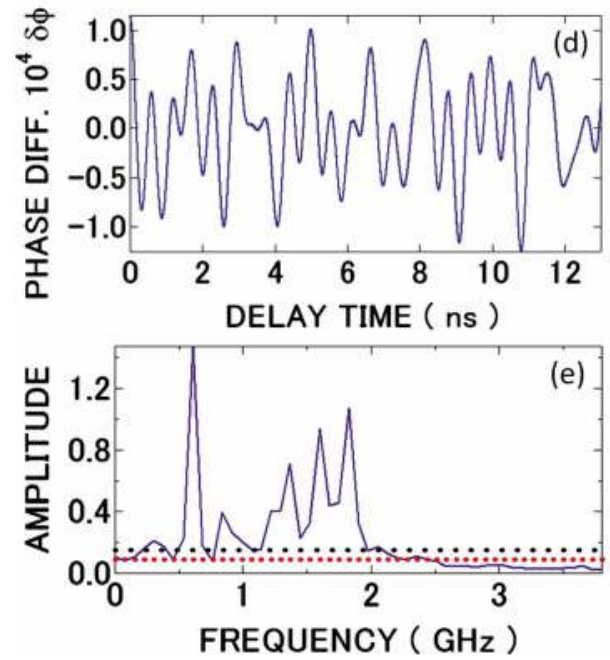

FIG. 2. (Color online) [(a)-(c)] Experimental time-resolved surface vibration images (arbitrary units) for a $220 \times 220 \mu \mathrm{m}^{2}$ region of the BAW resonator. The delay time zero is set arbitrarily. (d) Time scan plot for a single point. (e) Modulus (arbitrary units) of the temporal Fourier transform of (d). The upper and lower rows of dots correspond to the longitudinal wave resonances and the laser spectrum, respectively.

path Sagnac interferometer ${ }^{15}$ that focuses sets of two probe pulses separated in time by 100 ps to an $\sim 2 \mu \mathrm{m}$ diameter spot on the sample with a $\times 50$ objective lens (with an incident average power $\sim 5 \mathrm{~mW}$ ). The minimum detectable SAW wavelength is thus $\sim 2 \mu \mathrm{m}$, although this restriction does not apply to the through-thickness propagating longitudinal waves. By means of a two-axis rotating mirror and a lens pair, the optical probe spot is raster scanned over the device surface. The reflected optical probe pulses are combined at a photodetector to build up an image of the phase difference $\delta \phi=\delta \phi_{2}-\delta \phi_{1}$ between each pair of optical pulses (1 and 2) at a variety of pump-probe delay times. We thus effectively image the surface velocity normal to the plane of the device. The resolution in displacement at $300 \mathrm{~Hz}$ bandwidth is $\sim 0.1 \mathrm{pm}$. A $220 \times 220 \mu \mathrm{m}^{2}$ image requires $20 \mathrm{~min}$ to produce.

The cross section of the BAW resonator is shown in Fig. 1(c). ${ }^{16} \mathrm{~A} c$-axis oriented polycrystalline piezoelectric AlN layer of thickness $1.55 \mu \mathrm{m}$ and Pt electrodes of thickness $100 \mathrm{~nm}$ are sputtered onto a silicon on insulator (SOI) wafer with a thick top layer of $(100) \mathrm{Si}(30 \mu \mathrm{m})$. A $20 \mathrm{~nm} \mathrm{Ti}$ adhesion layer lies under the bottom Pt electrode. Part of the Si substrate (of thickness $0.52 \mathrm{~mm}$ ) is removed by deep reactive ion etching to leave the top $30 \mu \mathrm{m}$ layer of $\mathrm{Si}$ on the SOI silica layer (of thickness $2 \mu \mathrm{m}$ ). An optical micrograph is shown in Fig. 1(d), revealing the square (160 $\times 160 \mu \mathrm{m}^{2}$ ) active area of the device (defined by the AlN layer). The dark circular pads correspond to bonded contacts. (A small defect resides on the left hand side of this region.) The fundamental longitudinal resonance of the device is at $120.7 \mathrm{MHz}$ (corresponding to an equivalent longi-

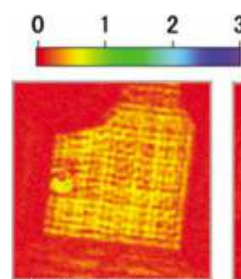

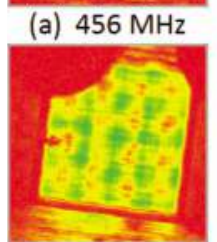

(d) $912 \mathrm{MHz}$

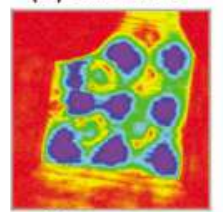

(g) $1368 \mathrm{MHz}$
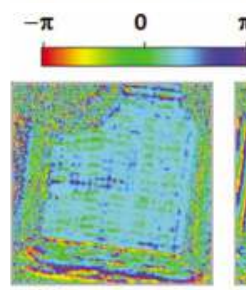

(j) $456 \mathrm{MHz}$

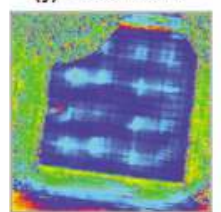

(m) $912 \mathrm{MHz}$

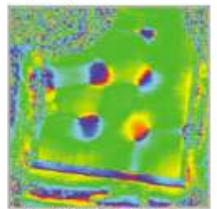

(p) $1368 \mathrm{MHz}$
$220 \mu \mathrm{m} \times 220 \mu \mathrm{m}$

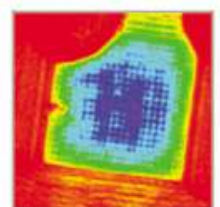

(b) $608 \mathrm{MHz}$

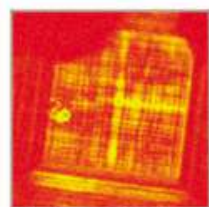

(c) $760 \mathrm{MHz}$

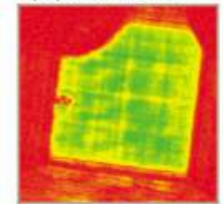

(e) $1064 \mathrm{MHz}$
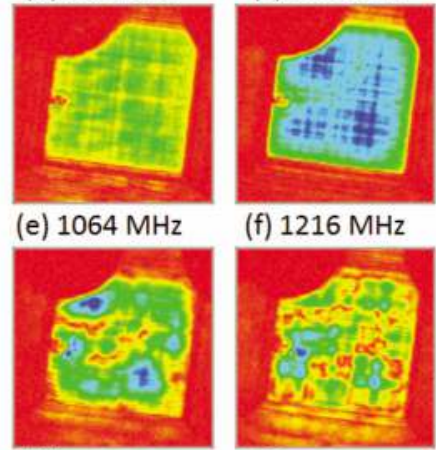

(h) $1520 \mathrm{MHz}$

(f) $1216 \mathrm{MHz}$

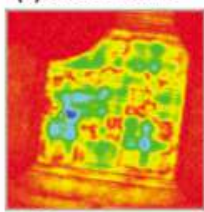

(i) $1672 \mathrm{MHz}$
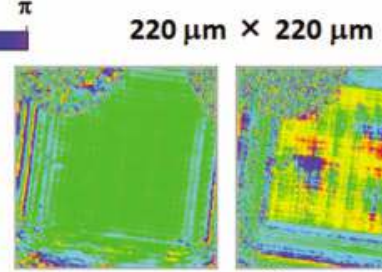

(k) $608 \mathrm{MHz}$

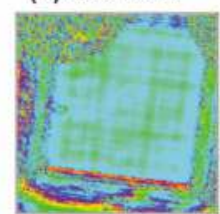

(n) $1064 \mathrm{MHz}$

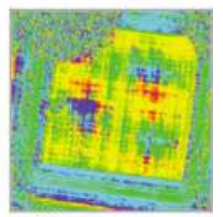

(I) $760 \mathrm{MHz}$

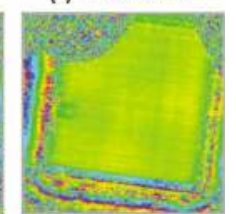

(o) $1216 \mathrm{MHz}$

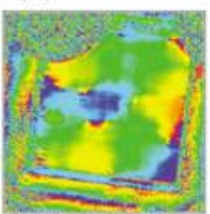

(q) $1520 \mathrm{MHz}$

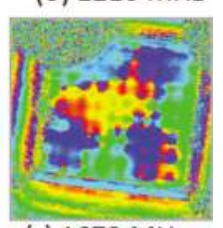

(r) $1672 \mathrm{MHz}$
FIG. 3. (Color online) Experimental amplitude (arbitrary units) [(a)-(i)] and phase [(j)-(r)] images at intervals of $152 \mathrm{MHz}$. The scale for (a)-(i) is the same except for (b) in which it runs from 0 to 7.

tudinal wave velocity of $\sim 8000 \mathrm{~ms}^{-1}$ over the stack $\mathrm{SiO}_{2} / \mathrm{Si} / \mathrm{Ti} / \mathrm{Pt} / \mathrm{AlN} / \mathrm{Pt}$ ). One of the high harmonics of this frequency, at $\sim 2 \mathrm{GHz}$, is typically chosen for device operation in practical applications. Electrical measurements show a broad envelope at $1.6 \pm 0.5 \mathrm{GHz}$ caused by the electromechanical resonance in the AlN film. The device, connected in parallel with a $50 \Omega$ terminator, is driven by a $0.3 \mathrm{~V}$ peak voltage (measured at $<1 \mathrm{GHz}$ bandwidth). The maximum detected interferometric output is $\sim 15 \mathrm{pm}$ expressed as a difference in displacement, or $\delta \phi \sim 2 \times 10^{-4}$.

Typical time-resolved surface vibration images are shown in Figs. 2(a)-2(c). The zero of the delay time is chosen arbitrarily (since the delay in the electronics was not determined). An animation of these images consisting of 60 frames over the $13.2 \mathrm{~ns}$ pulse-to-pulse interval can be viewed elsewhere. ${ }^{17}$ The complex patterns within the active area of the device evident in Figs. 2(a) and 2(c) result from mode conversion to in-plane guided modes such as generalized- 


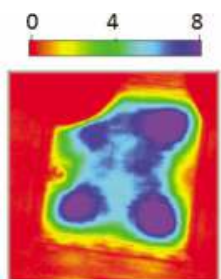

(a) $1824 \mathrm{MHz}$

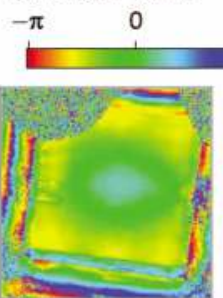

(d) $1824 \mathrm{MHz}$

0

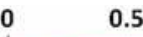

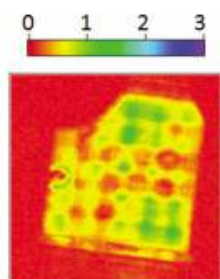

(b) $1976 \mathrm{MHz}$

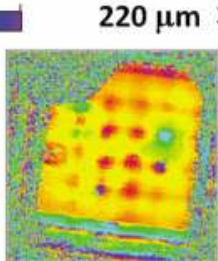

(e) $1976 \mathrm{MHz}$ 1

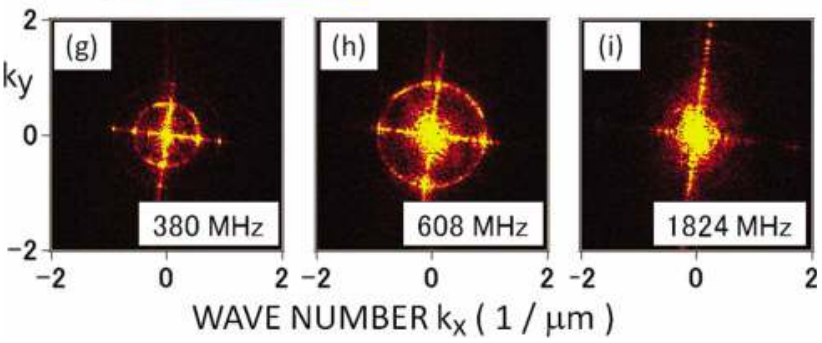

FIG. 4. (Color online) Amplitude (arbitrary units) [(a)-(c)] and phase [(d)-(f)] images at frequency intervals of $152 \mathrm{MHz}$ around $2 \mathrm{GHz}$. [(g)-(i)] Normalized modulus of the spatiotemporal Fourier transforms at three frequencies.

Rayleigh, Lamb, or Sezawa waves (from hereon termed SAWs for simplicity) that are multiply reflected at the device side walls. The loss of fourfold symmetry in Fig. 2(c) is caused by the circular pad that encroaches at the top left in Fig. 1(d). Outside the active area one can notice leakage in the form of SAWs. In Fig. 2(b) the vibration is dominated by a through-thickness longitudinal acoustic resonance, resulting at this time in a strong spatially uniform response.

Figure 2(d) shows a time scan of $\delta \phi$ from a single point at the center of the active area [see Fig. 1(d)]. The corresponding temporal Fourier transform is shown in Fig. 2(e). Strong resonances at 608, 1368, 1596, and $1824 \mathrm{MHz}$ are evident. Also shown are the positions of the principal high- $Q$ $(\sim 500$ at $2 \mathrm{GHz}$ with $50 \Omega$ termination) longitudinal resonances measured from the device electrical response [upper dots spaced at $120.7 \mathrm{MHz}$ - see Fig. 1(b)] and the peaks in the laser frequency spectrum (lower dots spaced at $76 \mathrm{MHz}$ ). At no point do these main longitudinal resonances and the optical excitation frequencies overlap sufficiently closely for resonant excitation, but subsidiary longitudinal resonances (owing to the presence of multilayers in the device) are observed at 608 and $1216 \mathrm{MHz}$, as shown below. Other resonances are caused by SAWs.

In the plots of Figs. 3 and 4(a)-4(f), the temporal Fourier transforms in both amplitude and phase reveal the mode patterns. ${ }^{17}$ The phase allows one to distinguish standing and traveling waves (the latter corresponding to the leakage outside the active area). Longitudinal resonances are dominant when the phase image shows a uniform response across the active area, for example, at 608 and $1216 \mathrm{MHz}$. At
$1824 \mathrm{MHz}$ the phase shows a radial dependence on distance from the center. This is presumably the effect of a SAW mode. The various spot patterns, for example, at $1368 \mathrm{MHz}$, arise from standing SAWs.

The modulus of the temporal and two-dimensional (2D) spatial Fourier transforms are shown for three frequencies in Figs. 4(g)-4(i) ${ }^{17}$ the circles in Figs. 4(g) and 4(h) correspond to a SAW (i.e., a guided mode) with a phase velocity of $\sim 4200 \mathrm{~ms}^{-1}$ for $k>0.5 \mu \mathrm{m}^{-1}{ }^{17}$ The bright spots at $\mathbf{k}$ $=\mathbf{0}(\mathbf{k}$ is the $2 \mathrm{D}$ wave vector) in Figs. 4(g)-4(i) correspond to the longitudinal resonances. In addition, we detect four spots at approximately $k_{x}, k_{y}= \pm 0.9 \mu \mathrm{m}^{-1}$ in Figs. $4(\mathrm{~g})$ and $4(\mathrm{~h})$ that correspond to the banded structure of period $\sim 7 \mu \mathrm{m}$ in Figs. 3(a) and 3(b), for example. We do not at present understand the origin of these frequency-independent features. The crosslike pattern in Figs. 4(g)-4(i), also seen elsewhere, ${ }^{8}$ arises from the vibration of the edges of the active area.

In conclusion, we have obtained real-time and (from temporal Fourier transforms) single-frequency vibrational images of a BAW resonator up to $\sim 2 \mathrm{GHz}$ with a hybrid electrical-excitation and ultrafast-optical-detection technique. In addition we have extracted the acoustic dispersion from spatiotemporal Fourier transforms. The use of lower repetition rates for the optical excitation would allow finer frequency resolution. Application to SAW devices is also feasible. Improvements in the photodetector response would allow higher frequency BAW devices to be probed, potentially up to frequencies $>100 \mathrm{GHz}$.

We are grateful to P. Muralt for the fabrication of the thin-film BAW resonator.

${ }^{1}$ E. Benes, M. Gröschl, F. Seifert, and A. Pohl, IEEE Trans. Ultrason. Ferroelectr. Freq. Control 45, 1314 (1998).

${ }^{2}$ R. Weigel, D. P. Morgan, J. M. Owens, A. Ballato, K. M. Lakin, K. Hashimoto, and C. C. W. Ruppel, IEEE Trans. Microwave Theory Tech. 50, 738 (2002).

${ }^{3}$ K. M. Lakin, G. R. Kline, and K. T. McCarron, IEEE Trans. Microwave Theory Tech. 41, 2139 (1993).

${ }^{4}$ T. Makkonen, A. Holappa, J. Ella, and M. M. Salomaa, IEEE Trans. Ultrason. Ferroelectr. Freq. Control 48, 1241 (2001).

${ }^{5}$ H. P. Loebl, C. Metzmacher, R. F. Milsom, P. Lok, F. V. Straten, and A. Tuinhout, J. Electroceram. 12, 109 (2004).

${ }^{6}$ W. Pang and H. Zhang, IEEE Trans. Ultrason. Ferroelectr. Freq. Control 52, 1239 (2005).

${ }^{7}$ H. Zhang, M. S. Marma, E. S. Kim, C. E. McKenna, and M. E. Thompson, IEEE Trans. Ultrason. Ferroelectr. Freq. Control 54, 1723 (2007).

${ }^{8}$ H. Safar, R. N. Kleiman, B. P. Barber, P. L. Gammel, J. Pastalan, H. Huggins, L. Fetter, and R. Miller, Appl. Phys. Lett. 77, 136 (2000).

${ }^{9}$ J. E. Graebner, B. P. Barber, P. L. Gamme, D. S. Greywall, and S. Gopani, Appl. Phys. Lett. 78, 159 (2001).

${ }^{10}$ K. L. Telschow, V. A. Deason, D. L. Cottle, and J. D. Larson, IEEE Trans. Ultrason. Ferroelectr. Freq. Control 50, 1279 (2003).

${ }^{11}$ J. V. Knuuttila, J. J. Vartiainen, J. Koskela, V. P. Plessky, C. S. Hartmann, and M. M. Salomaa, Appl. Phys. Lett. 84, 1579 (2004).

${ }^{12}$ K. Kokkonen and M. Kaivola, Appl. Phys. Lett. 92, 063502 (2008).

${ }^{13}$ Y. Sugawara, O. B. Wright, O. Matsuda, M. Takigahira, Y. Tanaka, S. Tamura, and V. E. Gusev, Phys. Rev. Lett. 88, 185504 (2002).

${ }^{14}$ D. M. Profunser, O. B. Wright, and O. Matsuda, Phys. Rev. Lett. 97, 055502 (2006).

${ }^{15}$ T. Tachizaki, T. Muroya, O. Matsuda, Y. Sugawara, D. H. Hurley, and O. B. Wright, Rev. Sci. Instrum. 77, 043713 (2006).

${ }^{16}$ J. Masson, G. Martin, R. Boudot, Y. Gruson, S. Ballandras, A. Artieda, P. Muralt, B. Belgacem, and L. Chomeloux, Proceedings of the IEEE Frequency Control Symposium, 2007, p. 741.

${ }^{17} \mathrm{See}$ http://kino-ap.eng.hokudai.ac.jp or EPAPS Document No. E-APPLAB-93-001852 for more data. For more information on EPAPS, see http://www.aip.org/pubservs/epaps.html. 